\title{
POLÍTICAS PÚBLICAS TRIBUTÁRIAS COMO INSTRUMENTO DE REDUÇÃO DAS DESIGUALDADES SOCIAIS: RUMO AO DESENVOLVIMENTO SUSTENTÁVEL
}

\author{
Joana D'Arc Dias Martins* \\ Maria de Fátima Ribeiro ${ }^{* *}$
}

\begin{abstract}
Resumo
$\mathrm{O}$ artigo objetiva analisar as políticas públicas tributárias como instrumento de combate a pobreza e redução das desigualdades sociais, objetivos preconizados na Agenda 2030 e na $\mathrm{CF} / 88$. Para tanto, será dado um especial destaque ao mínimo existencial - corolário da dignidade humana - como limite externo à ao princípio da capacidade contributiva. Diante da violação dessa garantia, ela poderá ser reivindicada em Juízo, por ser indispensável ao gozo de uma vida digna. A metodologia utilizada nesta pesquisa, quanto aos meios, foi desenvolvida mediante o método dedutivo, descritivo e qualitativo, através da revisão bibliográfica, doutrinária e jurisprudencial.
\end{abstract}

Palavras-chave: tributo; capacidade contributiva; mínimo existencial; desenvolvimento sustentável; controle judicial.

\section{PUBLIC TAX POLICIES AS AN INSTRUMENT TO REDUCE SOCIAL INEQUALITIES: TOWARDS SUSTAINABLE DEVELOPMENT}

\begin{abstract}
The article aims analyze public tax policies as an instrument to combat poverty and reduce social inequalities, objectives advocated in Agenda 2030 and CF/88. To this end, special emphasis will be given to the existential minimum - corollary of human dignity - as an external limit to the principle of contributory capacity. In view of the breach of this guarantee, may be claimed in court, as is indispensable for the enjoyment of a dignified life. The methodology used in this research, regarding the means, was developed through the deductive, descriptive and qualitative method, through the bibliographic, doctrinal and jurisprudential review.
\end{abstract}

Keywords: tribute; contributory capacity; existential minimum; sustainable development; judicial control.

\section{Introdução}

\footnotetext{
* Doutoranda e mestre em Direito pela Universidade de Marília - UNIMAR - Marília - São Paulo (Brasil). Especialista em Direito Ambiental pelo Instituto o Direito por um Planeta Verde, Especialista em Direito Público pela Ulbra, campus de Ji-Paraná/RO e em Direito Processual Civil pelo Instituto de Ensino Superior da Amazônia e Centro de Atualização e Estudos Jurídicos de São Paulo. Promotora de Justiça do Estado do Acre.

** Doutora em Direito Tributário pela PUC-SP, Pós Doutora em Direito Fiscal pela UL - Lisboa, Professora do Programa de Mestrado e Doutorado em Direito da Universidade de Marília - UNIMAR - Marília - São Paulo (Brasil).
} 
O papel do tributo em uma sociedade contemporânea não é somente financiar o Estado, mas, primordialmente, servir de instrumento de transformação social e concretização do princípio da dignidade da pessoa humana.

Nesse sentido, a política pública tributária, além de proporcionar uma igualdade de oportunidades entre os indivíduos, como uma "política de Estado" - cuja estrutura e funcionamento se encontra mergulhada na legalidade constitucional -, também deve se voltar ao combate à pobreza e redução das desigualdades entre posições sociais, objetivos preconizados na Agenda 2030 e na Constituição Federal de 1988.

Nada obstante, se de um lado a tributação é o meio que se vale o Estado para obter receitas indispensáveis ao atingimento de suas finalidades, por outro, há um espaço garantido pela dignidade humana em que a tributação não pode adentrar, sob pena de ofensa ao elemento nuclear do conteúdo essencial da dignidade, o mínimo existencial.

Nesse sentido, o princípio da capacidade contributiva, inspirado no ideal de justiça distributiva, representa o limite ao poder de tributar, implicando o reconhecimento de uma zona de mínimo vital na qual não pode haver, em hipótese alguma, tributação.

Outrossim, considerando que o Brasil, apesar de rico, é extremamente desigual, decorrente de uma má distribuição de renda e riquezas, o que se deve em grande parte ao modo como o sistema tributário se encontra estruturado no ordenamento jurídico, é objetivo deste artigo investigar qual o papel que a tributação vem desempenhando e se esse instrumento está contribuindo com a missão constitucional assumida pelo Estado brasileiro de erradicar a pobreza e diminuir as desigualdades sociais ou, ao contrário, ampliando esse quadro de iniquidades.

Em complemento, também é objetivo do estudo apontar os princípios da capacidade contributiva e progressividade, além de outros mecanismos, como instrumentos tributários que, corretamente empregados, têm potencial para influenciar na redução das desigualdades de renda.

Vale ressaltar que os direitos fundamentais, componentes do mínimo existencial tanto em sua faceta positiva quanto na negativa -, não se encontram na margem de discricionariedade dos Poderes Executivo e Legislativo, de modo que, diante da inércia dos referidos poderes, eles podem ser reivindicados em Juízo, por serem indispensáveis para a garantia de uma vida digna. 
Enfim, diante do princípio da intributabilidade do mínimo existencial, busca-se demonstrar que se o legislador, ao instituir determinada exação, o fizer de forma desarrazoada, fazendo incidir o gravame sob a parcela que o cidadão dispõe para o exercício de uma vida digna, caberá ao Poder Judiciário, como guardião das leis e da Constituição Federal, intervir de modo a assegurar a eficácia do primado da dignidade da pessoa humana, retirando o cidadão da ingerência estatal de riqueza não tributável.

A pesquisa se justifica principalmente pela atualidade e a relevância do tema. $\mathrm{O}$ método de abordagem é dedutivo e a técnica de pesquisa será bibliográfica. O trabalho está dividido em seis tópicos que seguem os seus objetivos específicos.

\section{Crescimento econômico $X$ desenvolvimento sustentável: muito além da renda}

Até meados do século $\mathrm{XX}$, o desenvolvimento era tratado simplesmente como sinônimo de crescimento econômico, medido por índices de incremento da produção de bens e serviços, como o aumento da renda per capita ou do Produto Interno Bruto (PIB). Havia, por conseguinte, uma nítida associação do desenvolvimento com o processo de industrialização que, nas nações desenvolvidas, grosso modo, de fato, representou uma melhoria das condições de vida da população.

Entretanto, a industrialização, que nos países ricos, foi capaz de, a um só tempo, implementar o crescimento econômico e a melhoria das condições de vida da população, não se refletiu do mesmo modo nas nações de industrialização tardia, tais como o Brasil. O crescimento econômico nesses países não se fez acompanhar da esperada eliminação da pobreza extrema ou da situação de desigualdade significativa entre as classes sociais. Ou seja, o progresso econômico não foi capaz de romper o desequilíbrio estrutural, ocasionando apenas um efeito modernizante.

O emprego do PIB per capita como único indicador para avaliar o desenvolvimento de um país é inadequado por ignorar questões da mais alta relevância para averiguar a qualidade de vida da população - tais como condições adequadas de alimentação, acesso à água potável, ao saneamento básico e aos serviços de educação e saúde (FUKUDA-PARR et al., p. 425-426). Daí se considerar que a expressão "desenvolvimento econômico" não é a mais adequada, haja vista a inexistência de desenvolvimento apenas de natureza econômica (GABARDO, 2002, p. 245). 
A constatação de que estava sendo calamitoso tratar o desenvolvimento simplesmente como aumento da renda per capta foi feita por vários economistas que entre os anos de 1960-1970 haviam conhecido de perto a realidade do "Terceiro Mundo", entre eles o paquistanês Mahbud ul Haq (1934-1988), diretor de projetos do Programa para o Desenvolvimento que a Oganização das Nações Unidas (ONU) criou em 1965 (PNUD).

À vista disso, principalmente a partir de 1990, com a elaboração do primeiro "Relatório do Desenvolvimento Humano", idealizado por Mahbud, juntamente com outros colaboradores, entre eles o indiano Amartya Sen, Nobel da Economia em 1998, já não seria mais possível admitir a ideia de crescimento econômico como sinônimo de desenvolvimento, pensamento típico dos séculos anteriores.

Tão larga experiência prática com os países subdesenvolvidos gerou em Mahbud ul Haq uma forte determinação em criar um indicador sintético que pudesse servir ao mundo como um guia do desenvolvimento, rivalizando, assim, com o PIB per capita. Buscava uma medida tão simples como o PIB - com uma única cifra - mas que não fosse tão cega no tocante aos aspectos sociais da vida humana. Assim nasceu o Índice de Desenvolvimento Humano (IDH), que além de medir a renda, capta, também, índices de longevidade e escolaridade (VEIGA, 2015, p. 14-15).

Uma vez superado o ultrapassado índice para medição de desenvolvimento econômico relacionado ao simples crescimento econômico, surgiu o IDH. Este novo índice, que mede renda, longevidade e educação, representou considerável progresso. Hoje ele é um dos principais indicadores do Relatório para o Desenvolvimento Humano - divulgado anualmente $^{1}$ - e considerado pela ONU como um importante instrumento no progresso do desenvolvimento humano no mundo. Todavia, segundo José Eli da Veiga (2015, p. 18/19), ele também padece de alguns vícios, dado que resulta da média aritmética dos três índices, sem considerar as questões sociais de modo particularizado. O próprio PNUD admite que o IDH é apenas um ponto de partida.

No mesmo sentido, após a ratificação do conceito de desenvolvimento sustentável na Conferência Rio-92, em de 2015, os 193 países membros da ONU, aprovaram os Objetivos de Desenvolvimento Sustentável (ODS) a serem concretizados até o ano de 2030. Esse documento é um compromisso dos países em tomar medidas mais dinâmicas para erradicar a

\footnotetext{
${ }^{1}$ De acordo com último relatório divulgado pelo PNUD, o Brasil caiu cinco posições e agora é o $84^{\circ}$ dos 189 países no ranking do IDH. Os dados do relatório atual são de 2019. No documento anterior, que analisou os dados de 2018 , o Brasil ocupava a $79^{\circ}$ da lista.
} 
pobreza e viabilizar ações de desenvolvimento em escala mundial (PLATAFORMA AGENDA 2030, 2019). Entre os importantes objetivos, os ODS's 1 e 10 - erradicar a pobreza e redução das desigualdades -, mostram-se como primordiais, em se tratando do estudo das políticas tributárias como instrumento de redução das desigualdades sociais e da garantia da proteção dos direitos fundamentais.

Observa-se, assim, que a definição contemporânea de desenvolvimento leva em 1 De acordo com último relatório divulgado pelo PNUD, o Brasil caiu cinco posições e agora é o $84^{\circ}$ dos 189 países no ranking do IDH. Os dados do relatório atual são de 2019. No documento anterior, que analisou os dados de 2018, o Brasil ocupava a $79^{\circ}$ da lista. consideração diversas dimensões, não se restringindo à seara econômica. A interdependência desta com a esfera humana e social é justamente um dos pontos cruciais do conceito, que o diferenciam da noção de crescimento puro e simples.

No Brasil, a Magna Carta, em seu art. 3. ${ }^{\circ}$, ao tratar dos objetivos fundamentais da República Federativa do Brasil, além de apontar a erradicação da pobreza e a redução das desigualdades sociais e regionais (inc. III), estabelece, em seu inciso II, a garantia do desenvolvimento nacional como sendo um dos seus propósitos. Depreende-se, de uma simples leitura desse dispositivo, que o constituinte elencou como objetivo fundamental da República brasileira não o simples desenvolvimento econômico, tido como sinônimo de crescimento econômico, mas, sim, o desenvolvimento nacional, bem mais amplo e abrangente que aquele, cujo objetivo fundamental não se restringe a um mero crescimento econômico, mas, acima de tudo, ao desenvolvimento de toda a nação brasileira.

Assim, a noção de desenvolvimento preconizada pela Constituição de 1988 diverge da visão marcadamente liberal difundida por volta dos anos 60. A satisfação ao conceito de desenvolvimento, para além da preocupação exclusiva com a opulência econômica e o desenvolvimento dos mercados, está intimamente ligada ao valor da solidariedade. Ou seja, vincula-se à busca da redução das desigualdades entre os cidadãos e, sobretudo, das distâncias entre as posições existentes na sociedade. Ademais, reclama a postura interventiva de uma Administração Pública inclusiva, por meio de ações universalizadas que possibilitem condições condignas a todos os cidadãos (HACHEM, 2013, p. 150-151). Desenvolver "sem deixar ninguém para trás". É com este apelo que encerra o texto da Agenda 2030. 
Raimundo Falcão (2013, p. 91) é enfático ao afirmar que desenvolvimento não é apenas crescimento econômico ou simples produção de riqueza. Desenvolvimento pressupõe distribuição ou redistribuição da riqueza em favor do bem-estar social.

No mesmo sentido, Amartya Sen (2000, p. 28-29) preceitua que o desenvolvimento transcende a acumulação de riqueza e o crescimento do PIB e de outras variáveis, simplesmente relacionadas à renda. $\mathrm{O}$ desenvolvimento deve estar diretamente ligado à melhora da vida que se leva e das liberdades desfrutadas.

Segundo Sen (2000), só há desenvolvimento quando os benefícios do crescimento servem à ampliação das capacidades humanas, entendidas como o conjunto das coisas que as pessoas podem ser ou fazer na vida. O seu objetivo básico deve ser ampliar as liberdades humanas, expandindo as escolhas que as pessoas possam fazer para ter vidas plenas e criativas. Sua concretização requer a remoção das principais fontes de privação de liberdade: pobreza, carência de oportunidades econômicas e destituição social sistemática, negligência dos serviços públicos e intolerância ou interferência de Estados repressivos.

Nada obstante, como não poderia deixar de ser - notadamente quando se está diante de países em desenvolvimento e, sobretudo, com tamanha desigualdade social como o Brasil , o apontado autor não considera que o desenvolvimento de uma nação prescinda do crescimento econômico, do aumento das rendas, da industrialização ou da modernização. Ao contrário, para Sen o crescimento econômico não é um fim em si mesmo, contudo, ele é um importante meio para promover a liberdade dos membros da sociedade, propiciando acesso a recursos indisponíveis para exercício de uma autonomia (SEN, 2000, p. 25-27) e, porque não dizer, ao exercício pleno da dignidade humana.

Por fim, resta compreendido que o caminho para o desenvolvimento sustentável modelo adotado pela Constituição Federal de $1988^{2}$ - passa necessariamente pela redução das desigualdades sociais. Para o objetivo deste artigo, o problema da desigualdade será analisado sob as lentes da tributação. Para esse desiderato, nos tópicos que se seguem, busca-se evidenciar que o atual modelo adotado no Brasil - com enfoque na tributação indireta -, além de fiscalmente injusto, é causa de injustiça social.

\footnotetext{
${ }^{2}$ A CF/88 buscou contemplar em um mesmo projeto político os três pilares do desenvolvimento sustentável, quais sejam: erradicar a pobreza e reduzir as desigualdades sociais (artigo $3^{\circ}$, I e II), estabelecimento de uma ordem econômica sustentável (artigo 170, VI) e o dever de tutela ecológica atribuída ao Estado e a sociedade (artigo 225, caput).
} 


\section{Brasil: subdesenvolvido apesar de rico}

O índice de desigualdade social de um país - acima da própria pobreza em si -, é o fator que mais impacta o bem estar da comunidade. A ampliação das desigualdades não gera consequências nefastas apenas para os pobres. Esse sentimento de injustiça acaba por contaminar toda a sociedade, acarretando o agravamento das divisões de classes e o consequente abalo da confiança entre desiguais (WILKINSON; PICKETT, 2010, p. 283-285).

Apesar de ser a $12^{\mathrm{a}}$ maior economia do mundo ${ }^{3}$, paradoxalmente, vem crescendo no Brasil o contingente de pessoas que vivem em situação de pobreza ou extrema pobreza, sendo inequívoco que o modo como o sistema tributário nacional se encontra estruturado no país contribui para esse quadro de iniquidades.

Em vista disso, pode-se dizer que o país, apesar de rico, prossegue subdesenvolvido, eis que paralelamente ao crescimento econômico, não se opera a melhoria das condições existenciais gerais da população, condição para ser considerado desenvolvido.

De acordo com levantamento de dados feito pelo Banco Mundial, em 2020 o Brasil figurava como o $9^{\circ}$ país mais desigual entre os 164 países selecionados, atrás apenas de alguns países africanos, como Moçambique, Suazilândia, República Centro-Africana, São Tomé e Príncipe, Zâmbia, Suriname, Namíbia e África do Sul (WORLD BANK, 2020).

Corroborando esses dados, o recém-lançado relatório "Síntese de Indicadores Sociais: Uma análise das condições de vida da população brasileira" do IBGE, ao analisar o índice Gini ${ }^{4}$, apontou que a partir de 2015, a desigualdade no Brasil passou a aumentar, tendência que se manteve até 2018. Em 2019, o índice Gini do rendimento domiciliar per capita do país foi de 0,543, recuando em relação a 2018 (0,545). Concernente à distribuição dos rendimentos, em 2019, os $10 \%$ mais ricos concentravam 42,9 da renda total do país e a parcela que compõe o grupo de $5 \%$ dos mais ricos, detinham $30,6 \%$ da renda - este grupo aumentou sua participação no rendimento total em 5,3\% entre os anos de 2015 e 2019 (29,1\% para $30,6 \%$ ). Nesse mesmo período a renda dos $10 \%$ mais pobres caiu $17 \%$, enquanto a do $1 \%$ mais rico cresceu $10 \%$ (IBGE, 2020, p. 50-60).

Em um círculo vicioso, a desigualdade econômica - desencadeada pela má distribuição de renda (onde a maioria dos recursos esta concentrada nas mãos de uma minoria

\footnotetext{
${ }^{3}$ Até o ano de 2020 o Brasil era a $10^{\mathrm{a}}$ maior economia do mundo. Contudo, o PIB brasileiro tombou $4,1 \% \mathrm{em}$ 2020, registrando a maior contração desde o início da série histórica atual do IBGE, iniciada em 1996.

${ }^{4} \mathrm{O}$ índice de Gini mede o grau de concentração de renda em determinado grupo e varia de 0 a 1 , sendo o "0" uma situação de completa igualdade e "l' uma situação de completa desigualdade.
} 
da sociedade) - é a fonte geradora de inúmeras desigualdades (alimentação, moradia, segurança, postos de trabalho, educação, saúde etc.), dado que a carência de recursos leva ao menor acesso ou acesso de pior qualidade a esses serviços.

Segundo Clemente Ganz Lúcio (2019), ex-diretor do Dieese, para reverter essa situação, a economia devia estar claramente orientada para um crescimento econômico com geração de emprego e crescimento dos salários, incremento da produtividade e uma estrutura tributária progressiva onde quem ganha mais paga mais impostos. Todavia, "No Brasil é o contrário, os mais pobres pagam proporcionalmente mais impostos que os mais ricos".

A progressividade tributária ${ }^{5}$ e o princípio da capacidade contributiva funcionam exatamente como instrumentos de redistribuição de rendas e redução das desigualdades sociais. Como pressuposto, ao tributar os detentores de patrimônio e renda na razão inversa da manifestação de riqueza e sobrecarregar a incidência dos tributos indiretos sobre o consumo gravame que pela sua própria natureza não fazem discriminação acerca da condição econômica do contribuinte -, o sistema tributário brasileiro encontra-se distanciado de uma lógica pautada na ideia de justiça fiscal e social (RIBEIRO, 2015).

Não há que se olvidar que esses objetivos somente poderão ser alcançado através de eficientes políticas públicas tributárias, que a par de preservar o patrimônio e a renda mínima da população mais pobre - garantindo condições dígnas de existência -, seja focada na progressividade dos impostos considerando a capacidade contributiva.

Perfilhando entendimento análogo, Medeiros, Souza e Castro (2014, p. 972) asseveram que as desigualdades sociais estão diretamente relacionadas ao modelo tributário adotado pelo país. Segundo os autores:

Os níveis de desigualdade de renda em uma sociedade afetam e são afetados por várias dimensões das políticas públicas. Por um lado, a desigualdade de renda está relacionada aos níveis de educação, saúde, nutrição, mortalidade, violência e várias outras características da sociedade, determinando e sendo determinada por elas. Por outro, a concentração ou não da renda estabelece como funciona, na prática, um sistema tributário que é a fonte de recursos para praticamente todas as políticas públicas. Não há dúvidas, portanto, que o tema tem impactos que vão muito além da dinâmica econômica.

\footnotetext{
${ }^{5}$ Um imposto é progressivo quando a alíquota de tributação se eleva quando aumenta o nível de renda. A carga tributária é regressiva quando diminui com o aumento da renda, e proporcional quando a carga tributária se mantém constante para qualquer valor de renda.
} 
Outrossim, diante da desigualdade social e econômica que grassa no país, decorrente de uma má distribuição de renda e riquezas, faz-se necessário perquirir qual o papel que a tributação vem desempenhando no Brasil. E mais, se este instrumento está servindo para diminuir as desigualdades ou, ao contrário, contribuindo para ampliar esse quadro.

Por fim, mostra-se relevante investigar os aspectos que levaram a esta situação - tal como o modo em que se encontra estruturado o sistema tributário brasileiro -, bem como traçar um paralelo entre as políticas públicas com os objetivos fundamentais elencados na Constituição Federal, entre eles a garantia do mínimo existencial.

\section{A estrutura do Sistema Tributário brasileiro e o distanciamento do ideal de justiça}

fiscal

De acordo com Thomas Piketty, a adoção um sistema tributário progressivo é um importante instrumento de redistribuição de rendas e combate à desigualdade social. Outrossim, com vistas ao estabelecimento de um sistema alinhado com a ideia de justiça social e liberdade individual, o autor sugere o aumento da tributação sobre o patrimônio e a renda, com desoneração do consumo (PIKETTY, 2014, p. 504).

Mesmo pensadores liberais como John Rawls (1997, p. 307) - que embora defendesse a proporcionalidade como um dos princípios da justiça como equidade, sob o argumento de que essa modalidade de tributação seria a mais adequada ao estímulo da produção -, reconheceu que nos sistemas tributários de países em que haja maior desigualdade social, a progressividade dos impostos sobre a renda é medida exigida pelos princípios da liberdade, da igualdade equitativa de oportunidades e da diferença. Igualmente, conquanto Klaus Tipke (1984, p. 527) entenda que a progressividade rompe com a igualdade, reconhece que esse rompimento é justificado pelo princípio do Estado Social, que tem por objetivo a distribuição de riquezas.

Trilhando o mesmo entendimento, Ribeiro (2015, p. 7-8) afirma que o combate às desigualdades sociais pela via da tributação pode se dar não apenas pela redistribuição de renda - através de prestações positivas aos mais pobres oriundas de recursos orçamentários obtidos por meio da tributação dos mais ricos -, mas, também, pela distribuição de rendas, 
baseada nas receitas e na ideia de divisão justa do ônus fiscal pela capacidade contributiva, por meio da progressividade, a fim de evitar a concentração de renda. ${ }^{6}$

Seja em sua faceta redistributiva ou distributiva, o que resta patente é que as políticas públicas tributárias são importantes instrumentos para efetivar e propiciar condições plenas para resgatar a dignidade da população e a redução das desigualdades entre as posições sociais, e não apenas permitir a sobrevivência.

Para tecer considerações sobre a natureza de um sistema tributário, a partir da ideia de equidade, a priori, faz-se necessária investigar as perspectivas que possibilitem a identificação do perfil do sujeito que de fato participa da arrecadação, e em que montante realiza essa participação. Nesse sentido, saber o tipo de riqueza que costuma ser tributada traz elementos fundamentais à análise com vistas à identificação do caráter de justiça do sistema tributário (PORTELLA; GUIMARÃES, 2020, p. 115). No mesmo sentido, Ribeiro (2015, p. 12) assevera que:

A justiça de um sistema tributário está na adequada distribuição da carga tributária entre os detentores de patrimônio e renda de um lado, e aqueles que nada têm, senão despesas, de outro. Os objetivos de cada sociedade vão presidir tais escolhas que desaguarão na formulação do seu sistema tributário.

Com efeito, é exatamente através da renda e da propriedade que é possível mensurar de forma precisa o grau de opulência econômica de um determinado contribuinte. Em vista disso, a tributação que incide sobre tais riquezas possibilita um maior alinhamento com a ideia de justiça fiscal. À contrario sensu, o nível de consumo de um determinado indivíduo, conquanto seja um indicativo importante da sua riqueza, somente de forma indireta e imprecisa possibilita o aferimento dessa condição. Consequentemente, a tributação sobre o consumo favorece a acumulação de capital, sendo um meio inferior de promoção da justiça distributiva (MURPHY; NAGEL, 2005, p. 156).

Fato incontroverso é que as pessoas que estão na base da pirâmide utilizam a maior parte de seus rendimentos na aquisição de bens de consumo, geralmente composto de itens essenciais à sua própria sobrevivência. Na perspectiva da tributação isso significa que a

\footnotetext{
${ }^{6}$ Torres $(2005$, p. 348$)$ distingue entre os princípios da distribuição e da redistribuição de rendas. Este último teria natureza orçamentária: "Leva em conta simultaneamente as vertentes da receita e da despesa, ao fito de transferir renda dos mais ricos para os pobres e miseráveis. Opera sob a consideração da justiça por transferência, particular subprincípio da justiça distributiva". Já o princípio da distribuição de rendas não se ocupa com as transferências, mas com a tributação de acordo com a capacidade do contribuinte e sua justiça.
} 
incidência dos tributos sobre o consumo oneram, proporcionalmente, mais tais pessoas, o que em termos técnicos se denomina regressividade tributária.

E para piorar, o produto da arrecadação tributária não é suficientemente investidos pelo Estado na promoção de políticas públicas que garantam à população mais carente os direitos sociais previstos constitucionalmente. Conforme ranking divulgado pelo Instituto Brasileiro de Planejamento Tributário (IBPT), o Brasil é o país com o menor índice de retorno de bem-estar à sociedade (ORTEGA, 2021).

A carga tributária do Brasil, diferentemente do que é comumente propalado, não é “a mais alta do mundo", sendo comparável à média da OCDE e dos países desenvolvidos, girando em torno de 35,21\% (RECEITA FEDERAL, 2018, p. 14). Porém, o que se deve atentar não é para o tamanho da carga tributária, e sim pela sua composição que cristaliza as desigualdades e pelo retorno à sociedade. No Brasil, diferentemente da maioria dos países desenvolvidos, a tributação sobre o consumo é muito superior à que incide sobre a renda (RIBEIRO, 2015, p. 10-12).

Destarte, o sistema tributário brasileiro, distanciando-se do ideal de justiça fiscal, é altamente regressivo, com prevalência da tributação sobre o consumo, em detrimento da tributação sobre renda e propriedade. Segundo dados colhidos junto à Receita Federal, referente à carga tributária no ano de 2018, cerca de $25 \%$ da arrecadação no país foi oriunda da incidência sobre renda e propriedade, enquanto algo em torno de $50 \%$ decorreu da incidência sobre consumo de bens e serviços (RECEITA FEDERAL, 2018, p. 6).

Corroborando esse entendimento, Hugo de Brito Machado (2009, p. 26) afirma que “A tributação recai de forma proporcionalmente mais pesada sobre a classe média, enquanto as políticas governamentais somente contemplam programas assistencialistas, ao invés de lançar bases estruturais para um desenvolvimento social sustentável”.

Denota-se, por conseguinte, que o modo como o sistema tributário se encontra estruturado no Brasil - sobrecarregando o consumo em detrimento da renda e da propriedade - tem como escopo atender aos interesses de arrecadação do Estado, a partir da perspectiva liberal de neutralidade e de eficiência econômica, e não à ideia de justiça fiscal, de combate à desigualdade ou de fortalecimento do Estado Social.

Como bem salientado por Ribeiro (2015, p. 35), não há que se olvidar que o sistema tributário brasileiro é "marcado por uma iniquidade regressiva escondida por trás do discurso hegemônico quanto ao caráter asfixiante de uma carga tributária afugentadora dos 
investimentos". Imperioso desmontar essas armadilhas construídas pelos beneficiários da concentração de renda, promovendo a maior tributação do patrimônio, heranças e rendas dos mais ricos a fim de aliviar a carga fiscal dos consumidores e dos assalariados.

Nesse diapasão, a política tributária pode ser eficazmente utilizada como instrumento de redistribuição de rendas, para tanto, faz-se necessária uma reforma tributária pro societate e não, tão somente, pro fisco. Só assim haverá efetivamente justiça fiscal, propiciadora de uma redistribuição de renda e de justiça social.

Todavia, conforme alertado por Domingos e Cunha (2013, p. 20), diante da crise institucional estabelecida no Brasil, mesmo que a arrecadação seja efetivada de forma adequada e se tenha uma distribuição coerente dos tributos auferidos, não haverá justiça social enquanto persistirem os inúmeros desvios de verbas e o sangramento dos cofres públicos.

Em suma, não se trata, portanto, apenas de arrecadação ou distribuição dos tributos, mas também de uma adequada gestão dos valores, dado que, apenas com a convergência de todos estes elementos será possível se pensar em uma efetiva justiça social tributária.

\section{Capacidade contributiva: limitação constitucional ao poder de tributar}

Nas democracias, a tributação é condição para a própria sobrevivência do Estado. É o meio que ele se utiliza para obter fonte de receita indispensável à implementação das diversas políticas públicas visando à concretização do bem comum. Contudo, o poder de tributar tem limites, entre eles a capacidade contributiva.

A tributação, além de não poder retirar a condição de desenvolvimento econômico de uma sociedade pela máxima tributação (tributação confiscatória), tampouco pode ser irrisória a ponto de impossibilitar os recursos necessários para uma redistribuição da renda e para equalização das diferenças sociais, sob pena de se transformar em um elemento agravante das distorções econômico-sociais em uma sociedade (COSTA-CORRÊA, 2017, p. 125). Esse equilíbrio é o que Hack (2007, p. 5) denominou de sustentabilidade da tributação.

Não se pode descurar que a busca pela melhoria das condições sociais dos membros de uma sociedade perpassa necessariamente pela ampliação da igualdade de oportunidades. Nesse tocante, o tributo representa um dos mais destacados instrumentos para a correção das distorções sociais e diferenciação social/funcional. Malgrado, para que possa atingir esses objetivos, de vital importância considerar a capacidade contributiva dos contribuintes, de 
modo a onerar de forma equivalente às distorções da capacidade econômica de seus membros (VITA, 2014, p. 662).

O princípio da capacidade contributiva - inspirado no ideal de justiça distributiva -, está previsto no artigo $145, \S 1^{\circ}$, da Constituição Federal de 1988, representando o vínculo essencial entre a tributação e a solidariedade social - considerado um dos sustentáculos do Estado Democrático de Direito (YAMASHITA, 2005, p. 59-60). Ou seja, o contribuinte cumpre com seu dever de solidariedade no meio social quando efetivamente contribui para a manutenção dos gastos estatais - através do recolhimento dos tributos que lhe são exigíveis na exata medida de suas possibilidades. Portanto, pelos ditames da justiça social, deve haver uma cooperação entre a sociedade visando o bem comum.

O ajuste ao princípio da capacidade contributiva passa por limitadores externos, de observância cogente, os quais são o mínimo existencial, em uma das extremidades, e o confisco, na extremidade oposta. Nesse tocante, Ricardo Lobo Torres (1995, p. 138) leciona que "a capacidade contributiva começa além do mínimo necessário à existência humana digna e termina além do limite destruidor da propriedade".

Dito de outra forma, a capacidade contributiva é o limite constitucional ao poder de tributar. Assim como o princípio da reserva de lei estabeleceu um limite formal à tributação, o princípio da capacidade contributiva estabeleceu um limite material: onde não houver capacidade contributiva, não deve haver tributação.

Como corolário, se de um lado a tributação é um instrumento para a concretização dos mandamentos constitucionais voltados à satisfação do bem comum, por outro, há um espaço garantido pela dignidade humana em que a tributação não pode adentrar, sob pena de ofensa a um dos elementos que compõe o conteúdo essencial da dignidade: o mínimo existencial.

No que diz respeito ao mínimo existencial como limite externo do princípio da capacidade contributiva - interesse maior deste artigo -, essa interpretação implica no reconhecimento de uma zona de mínimo vital - limitadora material da atuação tributária -, na qual não pode haver, em hipótese alguma, tributação. Embora não esteja previsto expressamente na Constituição, a sua tutela está implícita no ordenamento jurídico, consubstanciado no direito à vida e na dignidade da pessoa humana. Como pressuposto, aquelas pessoas, cujos rendimentos não ultrapassam o mínimo existencial, tudo o que se 
recebem é essencial para o seu sustento próprio, e como tal não deveriam pagar tributo algum (PESSÔA, 2011, p. 173).

Destarte, o princípio da capacidade contributiva e o mínimo existencial estão intrinsecamente relacionados, uma vez que a existência da capacidade para contribuir somente é aferível quando, no caso concreto, há riqueza acima do mínimo vital. Nesse sentido, Buffon (2009, p. 181) preleciona que:

[...] em qualquer modelo estatal - e no Estado Social principalmente - é inadmissível que o cidadão desprovido de capacidade para prover o seu próprio sustento seja compelido a contribuir para o Estado, especialmente quando este lhe sonega aquilo de mais básico que prometeu prover (saúde, educação, segurança, habitação, salário digno, etc.).

Malgrado, a despeito dos impostos diretos, em regra, não incidirem em face das pessoas cuja renda não supera o mínimo vital, o mesmo não pode ser dito em relação aos impostos indiretos, tais como o ICMS e IPI, por exemplo. Nesses tributos, cuja característica principal é a regressividade, pelo fenômeno da repercussão fiscal, quem arca com o sacrifício econômico do imposto são os consumidores finais (contribuinte de fato), independente do seu poderio econômico.

Assim, enquanto a tributação direta - base do sistema tributário progressivo - atende ao princípio da capacidade contributiva, agravando de modo mais contundente as pessoas com maior capacidade econômica, ou contributiva, por outro lado a tributação indireta possui caráter nitidamente regressivo, onerando igualmente os mais ricos e os mais carentes. Exemplo disso é o ICMS, incidente, inclusive, sobre os produtos da cesta básica.

Infere-se, de modo inequívoco, que a tributação indireta viola o princípio da capacidade contributiva e, consequentemente, o direito ao mínimo existencial - elemento vital e básico para uma existência digna -, subtraindo do indivíduo o seu direito fundamental de prover a si e a seus familiares dos recursos elementares para seu desenvolvimento e a ampliação de suas capacidades.

Assim, o sistema tributário brasileiro, focado na tributação indireta, é um modelo, fiscal e, principalmente, socialmente injusto, responsável pela concentração de rendas e pelas iniquidades sociais que de modo tão cruel atingem boa parte da população, em manifesta afronta aos objetivos fundamentais da Carta Constitucional de 1988 - e dos ODS da Agenda 
2030, ratificados pelo Brasil -, em especial os objetivos de reduzir as desigualdades sociais e de erradicação da pobreza e marginalização.

Por outro lado, resta compreendido que os princípios da capacidade contributiva e progressividade são instrumentos tributários que, corretamente empregados, influenciam decisivamente na redução das desigualdades de renda.

\section{Mínimo existencial como corolário da dignidade da pessoa humana}

O mínimo existencial corresponde ao núcleo essencial dos direitos humanos fundamentais, destinado a assegurar as condições indispensáveis à subsistência da pessoa e ao exercício pleno de suas liberdades, razão pela qual não pode ser relativizado. Está intimamente ligado ao princípio da dignidade da pessoa humana, consistente no reconhecimento de que todos são importantes e merecedores do mesmo respeito e consideração por parte do Estado e da comunidade.

Para Torres (2009, p. 70) o mínimo existencial corresponde a um direito constitucional imediatamente exigível, “[...] condições mínimas de existência humana digna que não pode ser objeto de intervenção do Estado e que ainda exige prestações estatais positivas". Ainda, segundo o autor: "Sem o mínimo necessário à existência cessa a possibilidade de sobrevivência do homem e desaparecem as condições iniciais da liberdade. A dignidade humana e as condições materiais da existência não podem retroceder aquém de um mínimo".

Contudo, o mínimo existencial - indispensável para viver em condições de dignidade -, consoante já reconhecido expressamente na jurisprudência dos Tribunais Superiores pátrios ( $\mathrm{STF}$ e $\mathrm{STJ}^{7}$ ), não pode ser confundido com o mero "mínimo vital” ou "mínimo de sobrevivência”, e sim ao indispensável para viver uma vida plena. Nesse sentido, pontuam Sarlet e Fensterseifer (2020, p. 286): "Não deixar alguém sucumbir à fome certamente é o primeiro passo no tocante à garantia de um mínimo existencial, mas não é o suficiente para garantir uma existência digna”.

Sem a possibilidade de acesso a condições existenciais mínimas, não há que se falar no usufruto das liberdades reais ou fática, tampouco em um padrão de vida compatível com a

\footnotetext{
${ }^{7}$ No Recurso Especial 1.185.474-SC, sob a relatoria do Ministro Humberto Martins, restou consignado que o mínimo existencial não pode ser entendido apenas como o mínimo para a sobrevivência, tendo um conteúdo muito mais abrangente, para incluir condições socioculturais, com o escopo de assegurar uma inserção social mínima (RECUSO ESPECIAL 1.185.474- SC - 2010/0048628-4)
} 
dignidade humana, dado que um piso mínimo de condição existencial é imprescindível para o exercício dos demais direitos fundamentais em variadas vertentes (SARLET; FENSTERSEIFER, 2020, p. 285).

Nessa mesma linha, ao tratar sobre a capacidade contributiva como limite da tributação, Casalta Nabais (2015, p. 435) testifica que o legislador deve atender a um mínimo de igualdade como ponto de partida, permitindo que o cidadão satisfaça as necessidades primárias (alimentação, saúde etc.); e a um mínimo como ponto de chegada, para a obtenção de crescimento pessoal e atributos econômicos. Para o autor, o princípio tem dois significados: é pressuposto da tributação, ao se basear na capacidade econômica, representando um “mínimo lógico exigível”; e, por outro lado, é um parâmetro constitucional.

Logo, a fim de garantir uma vida com dignidade, o Estado deve atentar para o princípio da capacidade contributiva, cujo objetivo é justamente proteger o mínimo existencial. Por consequência, se a renda não ultrapassar esse patamar o cidadão não estará em condições de arcar com as despesas públicas por intermédio da contribuição. Tipke e Yamashita (2002, p. 34) asseveram que o mínimo existencial pode ser extraído da dignidade da pessoa humana e do Princípio do Estado Social, de modo que "O Estado não pode, como Estado Tributário, subtrair o que, como Estado Social, deve devolver”.

Nessas tintas, para a consecução desses objetivos, o Estado possui obrigações de natureza positiva e negativa. Na forma positiva, o mínimo existencial se revela através do dever de promover políticas públicas que garantam esse direito. Por sua vez, na forma negativa, o mínimo existencial se reflete no campo tributário como um direito subjetivo, contra a intervenção Estatal no patrimônio mínimo afetado para a consecução do mínimo existencial e a justa oportunidade de obter crescimento pessoal e econômico. Tratando das facetas positiva e negativa, Sarlet (2015, p. 101) aduz que "se o mínimo existencial é aquilo que o Estado, em todo o caso, deve assegurar positivamente, também é aquilo que o Estado deve respeitar por força de um dever de não intervenção".

Em suma, se um lado é vedado ao Estado tributar o mínimo essencial, indispensável a uma existência digna, por outro, é sua obrigação constitucional, no exercício de seus deveres nucleares, assegurar a todos, sem exceção, o direito ao mínimo existencial. Nada obstante, nem sempre o Estado administra os tributos com a eficiência necessária para cumprir com as promessas constitucionais de efetivação dos direitos fundamentais, mesmo aqueles tidos 
essenciais pela Constituição Federal, o que pode acarretar a intervenção do Poder Judiciário tendente a garantir tais direitos, conforme será tratado no tópico a seguir.

\section{Mínimo existencial a partir da perspectiva jurídica da sua justiciabilidade}

Conforme já dito alhures, o mínimo existencial - identificado como o núcleo sindicável da dignidade da pessoa humana, é um direito de eficácia plena, e como tal, passível de ser exigido judicialmente.

No tocante ao aspecto negativo do mínimo existencial, se o legislador, ao instituir determinada exação, o fizer de forma desarrazoada, fazendo incidir o gravame sob a parcela que o cidadão dispõe para o exercício de uma vida digna, ao Poder Judiciário caberá intervir de modo a assegurar a eficácia do primado da dignidade da pessoa humana, retirando o cidadão da ingerência estatal de riqueza não tributável.

Portanto, o princípio da intributabilidade do mínimo existencial também se direciona ao Poder Judiciário, dado que, verificando na situação concreta violação àquele patamar mínimo, tem por dever assegurar à pessoa a defesa desse mínimo, sobretudo quando a lesão ou ameaça atenta contra o princípio basilar da dignidade da pessoa humana.

Outrossim, frente aos direitos consagrados constitucionalmente, não há discricionariedade do administrador. Por trás da ideia de "poder" conferido ao Estado, há um subjacente "dever" ou "poder-dever", que devem ser compatíveis com os valores fundamentais do sistema constitucional. Essa constatação leva em conta o enfretamento de possíveis arbitrariedades estatais, bem como a redução da margem de liberdade do executivo, permeando sua atuação à realização dos direitos fundamentais dos cidadãos, e não apenas ao interesse estatal (BANDEIRA DE MELLO, 2007, p. 380).

No mesmo sentido, Maria Helena Costa (2012, p. 114) é categórica em afirmar a viabilidade de o magistrado, "diante de uma situação em que constatar a ausência de capacidade contributiva relativa ou subjetiva ou o excesso de carga fiscal sobre determinado sujeito, negar efeitos à lei impugnada in casu".

Consoante ponderações de Oliveira e Borges (2016, p. 12), excluir a possibilidade de proteção ao mínimo existencial pela via judicial do cidadão "que realizou a hipótese de incidência no caso singular é uma ofensa grave e frontal ao direito fundamental do acesso à justiça e uma negativa à efetivação do princípio da dignidade da pessoa humana, fundamento da República Federativa do Brasil”. 
Por conseguinte, a partir da perspectiva jurídica da sua justiciabilidade, vale ressaltar que os direitos fundamentais, componentes do mínimo existencial, não se encontram à disposição dos Poderes Executivo e Legislativo. Isso significa que, diante da inércia dos referidos poderes, eles podem ser reivindicados em Juízo, por serem indispensáveis para uma vida digna. Como preleciona Torres (2009, p. 82):

[...] o Judiciário pode determinar a entrega das prestações positivas, eis que tais direitos fundamentais não se encontram sob a discricionariedade da Administração ou do Legislativo, mas se compreendem nas garantias institucionais da liberdade, na estrutura dos serviços públicos essenciais e na organização de estabelecimentos públicos (hospitais, clínicas, escolas primárias, etc.).

Porém, ao se entender como possível exigir do Estado prestações básicas na esfera social, há que se considerar o entendimento de parte da doutrina brasileira de que a implementação de políticas públicas, por medidas judiciais, sofre notável ponderação diante da teoria da "reserva do possível". Ou seja, a escassez de recursos pode servir como fundamento para o Estado não efetivar alguns direitos.

Todavia, só se admite subordinar ao princípio orçamentário da "reserva do possível" àquelas medidas prestacionais que não estejam incluídas no núcleo essencial dos direitos fundamentais. No tocante ao mínimo existencial, consoante Clève (2003, p. 23), não é pertinente argumentar tais fundamentos, pois se trata de padrão mínimo indispensável para a garantia do princípio da dignidade da pessoa humana - pilar de toda a sistemática dos direitos humanos e fundamentais - devendo ser garantido em qualquer conjectura, dado que a eficácia normativa de tais direitos é extraída diretamente do comando constitucional, consubstanciado nos artigos $1^{\circ}$, inciso III e $3^{\circ}$ e incisos.

Esse mesmo entendimento pode ser extraída da paradigmática decisão monocrática do Supremo Tribunal Federal proferida na ADPF $n^{\circ}$ 45, da lavra do Ministro Celso de Mello (2004):

Não se mostrará lícito, no entanto, ao Poder Público, em tal hipótese mediante indevida manipulação de sua atividade financeira e/ou políticoadministrativa - criar obstáculo artificial que revele o ilegítimo, arbitrário e censurável propósito de fraudar, de frustrar e de inviabilizar o estabelecimento e a preservação, em favor da pessoa e dos cidadãos, de condições materiais mínimas de existência. Cumpre advertir, desse modo, que a cláusula da "reserva do possível" - ressalvada a ocorrência de justo motivo objetivamente aferível - não pode ser invocada, pelo Estado, com a finalidade de exonerar-se do cumprimento de suas obrigações 
constitucionais, notadamente quando, dessa conduta governamental negativa, puder resultar nulificação ou, até mesmo, aniquilação de direitos constitucionais impregnados de um sentido de essencial fundamentalidade.

Andréas Krell (2004, p. 83-85), igualmente, destaca que, a despeito das atividades concretas da administração depender de dotações orçamentárias prévias e do programa de prioridades estabelecidos pelo governante, o argumento da reserva do possível não é capaz de obstruir a efetivação judicial de normas constitucionais, ainda mais quando a norma conforma direito fundamental e conteúdo de dignidade humana, como é o caso da garantia ao mínimo existencial. Logo, diante da omissão da administração pública em implementar uma política pública, "o Judiciário tem não somente o poder, mas o dever de intervir".

Por fim, resta compreendido que a mesma dignidade, que autorizam ao Estado instituir tributos, serve-lhe também como limite, seja sob o aspecto negativo, impossibilitando o legislador de criar normas tributárias que adentrem na riqueza de quem não as possui, bem como o aspecto positivo, atribuindo ao cidadão a possibilidade de acionar o judiciário contra o avanço da carga tributária para fora das fronteiras delineadas pelo mínimo existencial.

\section{Considerações finais}

Conforme restou demonstrado, o Brasil, apesar de rico, é um dos países mais desiguais do mundo, com altos índices de concentração de renda em detrimento de uma grande parte da população que vive em condições aquém da dignidade humana. Esse quadro de iniquidades pode ser reduzido a partir de um sistema tributário mais equânime.

A carga tributária do Brasil, diferentemente do que se costuma dizer, não é "a mais alta do mundo", sendo comparável à média da OCDE e dos países desenvolvidos. Todavia, diferentemente da maioria dos países desenvolvidos, a tributação sobre o consumo é muito superior à que incide sobre a renda e patrimônio, contribuindo para o aumento das desigualdades de renda, dado que a carga tributária atinge significativamente a parcela da população de classe baixa e média. Logo, os efeitos regressivos acarretam problemas na distribuição de renda, bem como no acesso aos direitos básicos do cidadão brasileiro.

Não bastasse isso, o produto da arrecadação tributária também não se reverte suficientemente para a promoção de políticas públicas que garantam à população mais carente os direitos sociais previstos constitucionalmente. 
Outrossim, a despeito da tributação ser um dever fundamental - alicerçado na solidariedade social -, constituindo um instrumento para a concretização dos mandamentos constitucionais voltados à satisfação das necessidades humanas, há um espaço garantido pela dignidade humana em que a tributação não pode adentrar, sob pena de ofensa a um dos elementos que compõe o conteúdo essencial da dignidade.

Desse modo, o mínimo vital não se encontra no âmbito da discricionariedade da Administração Pública ou do Poder Legislativo, mas na liberdade do cidadão, no seu direito ao desenvolvimento e crescimento econômico, além da boa execução de serviços públicos essenciais.

Por fim, restou evidenciado que o limite insculpido pelo mínimo existencial, além de se voltar para o legislador - quando da instituição de determinada exação -, também se direciona ao Poder Judiciário que, verificando na situação concreta violação àquele patamar mínimo, deve assegurar à pessoa a defesa desse mínimo vital em deferência ao princípio da dignidade da pessoa humana.

\section{Referências bibliográficas}

BANDEIRA DE MELLO, Celso Antônio. Discricionariedade e controle jurisdicional. 2. ed.. São Paulo: Malheiros, 2007.

BRASIL. Supremo Tribunal Federal. Plenário STF - Medida Cautelar em Ação de Descumprimento de Preceito Fundamental: ADPF 45 DF, Relator: Min. CELSO DE MELLO. Data de Julgamento: 29/04/2004. Data de Publicação: DJ 04/05/2004 PP-00012 RTJ VOL-00200- 01 PP00191. Disponível em: https://stf.jusbrasil.com.br/jurisprudencia/14800508/medidacautelar-emarguicao-de-descumprimento-de-preceito-fundamental-adpf-45-df-stf. Acesso: 1 de jul. 2021.

BRASIL. RECEITA FEDERAL. Carga Tributária 2018. Disponível em: https://receita.economia.gov.br/dados/receitadata/estudos-e-tributarios-e-aduaneiros/estudoseestatisticas/carga-tributaria-no-brasil/ctb-2018-publicacao-v5.pdf. Acesso: 1 de jun. 2021.

BUFFON, Marciano. Tributação e Dignidade Humana: entre direitos e deveres fundamentais. Porto Alegre: Livraria do Advogado, 2009. CARRAZZA, Roque Antônio. Curso de Direito Constitucional Tributário. Ed. 25. São Paulo: Malheiros, 2009.

CLÈVE, Clèmerson Merlin. A eficácia dos direitos fundamentais sociais. Revista Crítica Jurídica, Curitiba, n. 22, p. 17-29, jul./dez. 2003.

COSTA-CORRÊA, André Luiz. Considerações sobre a eficiência tributária para uma tributação no século XXI. Revista Brasileira de Direito e Justiça./Brazilian Journal of Law and Justice, Revista Científica do Setor de Ciências Jurídicas da Universidade Estadual de Ponta Grossa. Ponta Grossa: Editora UEPG, 2017- 2017, 1 (1), p. 125-149, Jul./Dez. 2017. Disponível em: https://www.revistas2.uepg.br/index.php/direito/article/view/7348/209209209922. Acesso: 20 de jun. 2021. 
COSTA, Regina Helena. Princípio da Capacidade Contributiva. 2.ed. São Paulo: Malheiros, 2012.

DOMINGOS, Terezinha de Oliveira; CUNHA, Leandro Reinaldo da. A tributação como instrumento de concretização da dignidade da pessoa humana em face do desenvolvimento. (coord) TAVARES NETO, José Querino; FEITOSA, Raymundo Juliano Rego. 25 anos da Constituição Cidadã: Os Atores Sociais e a Concretização Sustentável dos Objetivos da República - Florianópolis: FUNJAB, 2013. p. 48-71 Disponível em: http://www.publicadireito.com.br/artigos/?cod=154aa6866aefb6f8. Acesso: 3 de jul. 2021.

FALCÃO, Raimundo Bezerra. Direito econômico (teoria fundamental). São Paulo: Malheiros Editores, 2013.

FUKUDA-PARR, Sakiko et al. Assessing State compliance with obligations to fulfill economic and social rights: a methodology and application to the states of Brazil. In: PIOVESAN, Flávia; SOARES, Inês Virgínia Prado (coords.). Direito ao desenvolvimento. Belo Horizonte: Fórum, 2010.

GABARDO, Emerson. Princípio constitucional da eficiência administrativa. São Paulo: Dialética, 2002.

HACHEM, Daniel Wunder. A noção constitucional de desenvolvimento para além do viés econômico: reflexos sobre algumas tendências do Direito Público brasileiro. A\&C - Revista de Direito Administrativo \& Constitucional, Belo Horizonte, v. 13, n. 53, jul./set. 2013, p. 133-168. Disponível em: http://www.revistaaec.com/index.php/revistaaec/article/view/126. Acesso: 1 de jul. 2021.

HACK, Érico. Sustentabilidade da tributação e a finalidade do tributo. II Seminário sobre Sustentabilidade da FAE. Curitiba: FAE, 2007.

IBGE. Síntese de Indicadores Sociais: uma análise das condições de vida da população brasileira. 2020/IBGE, Coordenação de População e Indicadores Sociais. - Rio de Janeiro: IBGE, 2020. Disponível em: https://biblioteca.ibge.gov.br/visualizacao/livros/liv101760.pdf. Acesso: 1 de jul. 2021.

KRELL, Andréas. Discricionariedade Administrativa e proteção ambiental. Porto Alegre: Livraria do Advogado, 2004.

LÚCIO, Clemente Ganz. Custo de vida, emprego e desemprego, cesta básica, tarifas públicas, salário mínimo: a análise do DIEESE. Jornal Brasil Atual. Entrevistadora Nahama Nunes. 10/2/2019. Disponível em: https://youtu.be/hiImc0k4Tgc. Acesso: 1 de jul. 2021.

MACHADO, Hugo de Brito. Curso de Direito tributário. 20 ed. São Paulo: Malheiros, 2009.

MEDEIROS, Marcelo; SOUZA, Pedro Herculano Guimarães Ferreira de. CASTRO, Fábio Ávila de; A estabilidade da desigualdade de renda no Brasil, 2006 a 2012: estimativa com dados do imposto de renda e pesquisas domiciliares. Scielo. 2014. Disponível em https://www.scielo.br/pdf/csc/v20n4/pt_1413-8123-csc-20-04-00971.pdf. Acesso: 28 de jun. 2021.

MURPHY, Liam; NAGEL, Thomas. O mito da propriedade - os impostos e a justiça. Trad. Marcelo Brandão Cipolla. São Paulo: Martins Fontes, 2005.

NABAIS, José Casalta. O Dever fundamental de pagar impostos. Coimbra: Almedina, 2015. 
OLIVEIRA, Alexandre Machado de; BORGES, Antônio de Moura. Limitações ao Princípio da Capacidade Contributiva: Mínimo Existencial e Confisco. Conpedi Law Review. Uruguai. v. 2. n. 4. Jul/dez 2016. 2 p. 180-200. Disponível em: https://www.indexlaw.org/index.php/conpedireview/article/view/3660. Acesso: 1 de jul. 2021.

ORTEGA, Fabiana. Brasil tem o pior retorno de impostos à sociedade, segundo estudo; veja ranking. 2/4/2021. Investnews. Disponível em: https://investnews.com.br/economia/brasil-tem-o-pior-retornodeimpostos-a-sociedade-segundo-estudo-veja-ranking/. Acesso: 4 de jul. 2021.

PESSÔA, Leonel Cesarino. Redução da desigualdade, política tributária e a Constituição. Revista Brasileira de Direito Constitucional. RBDC N. 18 - jul./dez. 2011. p. 167. 182. Disponível em http://www.esdc.com.br/RBDC/RBDC-18/RBDC-18-007-INDICE.htm. Acesso: 4 de jul. 2021.

PIKETTY, Thomas. O Capital no Século XXI. Trad. Mônica Baumgarten de Bolle. Rio de Janeiro: Intrínseca, 2014.

PlATAFORMA AGENDA 2030. Conheça a Agenda 2030: o plano de ação global para mudar o mundo até 2030. Disponível em: http://www.agenda2030.com.br/sobre/. Acesso: 10 de jun. 2021.

$\begin{aligned} & \text { PNUD. PROGRAMA DE DESENVOLVIMENTO DAS NAÇÕES UNIDAS. Relatórios de } \\ & \text { Desenvolvimento }\end{aligned}$
Humano. http://hdr.undp.org/en/sites/default/files/hdr_2019_pt.pdf. Acesso: 30 de jun. 2021.

RAWLS, John. Uma Teoria da Justiça. São Paulo: Martins Fontes, 1997.

RIBEIRO, Ricardo Lodi. O capital no século XXI e a justiça fiscal: uma contribuição de Thomas Piketty para uma reforma tributária no Brasil. Revista de Direito Público da Economia - RDPE, Belo Horizonte, ano 13, n. 50, p. 197-228, abr./jun. 2015.

SARLET, Ingo Wolfgang. Dignidade (da pessoa) humana e direitos fundamentais na Constituição Federal de 1988. 10. ed. Porto Alegre: Livraria do Advogado Editora, 2015.

SARLET, Ingo Wolfgang; FENSTERSEIFER, Tiago. Curso de Direito Ambiental. Rio de Janeiro: Forense. 2020.

SEN, Amartya. Desenvolvimento como liberdade. Tradução de Laura Teixeira Motta; revisão técnica Ricardo Doniselli Mendes. São Paulo: Companhia das Letras, 2000.

TIPKE, Klaus. Princípio da Igualdade e a Ideia de Sistema no Direito Tributário. In: BRANDÃO MACHADO (coord.). Estudos em Homenagem ao Prof. Ruy Barbosa Nogueira. São Paulo: Saraiva, 1984, p. 517-527.

TIPKE, Klaus; YAMASHITA, Douglas. Justiça Fiscal e Princípio da Capacidade Contributiva. São Paulo: Malheiros, 2002.

TORRES, Ricardo Lobo. O direito ao mínimo existencial. Rio de Janeiro: Renovar, 2009.

TORRES, Ricardo Lobo. Os Direitos Humanos e a Tributação: imunidades e isonomia. Rio de Janeiro: Renovar, 1995.

TORRES, Ricardo Lobo. Tratado de Direito Constitucional Financeiro e Tributário, vol. II. Valores e Princípios Constitucionais Tributários. Rio de Janeiro: Renovar, 2005. 
VALLE, Maurício Dalri Timm do; AVEIRO, Júlio da Costa Rostirola. O mínimo existencial e a tributação. Revista de Direito Internacional Econômico e Tributário - RDIET, Brasília, v. 12, no 2, jul-dez, 2017. p. 76-123.

VEIGA, José Eli da. Para entender o desenvolvimento sustentável. São Paulo: Editora 34, 2015.

VITA, Jonathan Barros. As novas funções dos tributos no sistema social: distributividade como forma de promoção da democracia e da liberdade. In: GRUPENMACHER, Betina Treiger (org.). Tributação: democracia e liberdade - em homenagem à Ministra Denise Martins Arruda. São Paulo: Noeses, 2014. p. 659-678.

WILKINSON, Richard e PICKETT, Kate. O Espírito da Igualdade - Porque Razão as Sociedade Mais Igualitárias Funcionam Quase Sempre Melhor. Trad. Alberto Gomes. Lisboa: Editorial Presença, 2010. WORD BANK. World development indicators. Washington, DC (2020). Disponível em: http://wdi.worldbank.org/table. Acesso: 1 de abr. 2021.

WORD BANK. World development indicators. Washington, DC (2020). Disponível em: http://wdi.worldbank.org/table. Acesso: 1 de abr. 2021. 